\title{
Morphometry of the Human Placenta in Mining and Non-Mining Areas in Northwestern Tanzania; A Comparative Cross-Sectional Study
}

\author{
Mary Ndibalema ${ }^{1,2}$, Erisa Mwaka', Peter Rambau ${ }^{3}$, Ian Munabi', William Buwembo ${ }^{1}$ \\ ${ }^{1}$ Department of Anatomy, School of Biomedical Sciences, Makerere University, P.O.BOX 7072 Kampala, Uganda, ${ }^{2}$ Department of Anatomy, Weil Bugando \\ School of Medicine, Catholic University of Health and Allied Sciences, P.O.BOX 1464, Mwanza, Tanzania, ${ }^{3}$ Department of Pathology, Weil Bugando \\ School of Medicine, Catholic University of Health and Allied Sciences, P.O.BOX 1464, Mwanza, Tanzania.
}

\section{Abstract}

Introduction: Placenta morphometry varies with increased heavy metal concentrations among other factors. There is limited knowledge on the effect of perceived heavy metal exposure due to mining activities on placenta morphometry specific to the Tanzanian population. The study thus aimed to determine the morphometric characteristics of the human placenta and the association between placental weight with maternal factors in mining and non-mining areas in Northwestern Tanzania. Subjects and Methods: This was a comparative crosssectional study conducted in Mwanza and Geita regions of Northwestern Tanzania representing the mining and non-mining areas, respectively. Included in the study were placentas from 490 mothers, residing in the respective areas throughout pregnancy. Comparison of the placenta morphometric variables between the two groups was made using the independent sample t-test, and association between the maternal factors and placenta weight was done using multi-level linear analysis. Results: The mean placenta weight in the non-mining and mining areas was $465.9 \pm 101.2 \mathrm{~g}$ and $443.6 \pm 82.7 \mathrm{~g}$, and the mean thickness was $1.52 \pm 0.32 \mathrm{~cm}$ and $1.61 \pm 0.38 \mathrm{~cm}$ respectively. The mean diameter in the non-mining and mining areas was $19.0 \pm 1.9 \mathrm{~cm}$, the mean cotyledon number was $20 \pm 5$ and $19 \pm 4$, and the mean cord length was $49.0 \pm 12.7 \mathrm{~cm}$ and $50.1 \pm 10.4 \mathrm{~cm}$ respectively. With the exception of cord length, the differences in the morphometric parameters in the non-mining and mining areas were significant $\mathrm{p}<0.5$. Increase in maternal weight on booking and maternal age were associated with corresponding increase in placenta weight. Conclusion: The findings of this study seem to suggest that heavy metal exposure due to mining activities does affect placenta growth.

Keywords: Morphometry, heavy metal exposure, mining, placenta growth.

Corresponding Author: Mary Ndibalema, Department of Anatomy, School of Medicine, Catholic University of Health and Allied Sciences, P.O. Box 1464 Mwanza-Tanzania.

Email: ndibalemamary@gmail.com

Received: May 2020

Accepted: May 2020

\section{Introduction}

The human placenta is an organ of fetal origin, providing interchange of materials between the mother and fetus, thus making it one of the most important factors that determine fetal well-being. ${ }^{[1]}$ In order to support perinatal life, the placenta undergoes different changes in weight, volume, structure, shape, and function continuously throughout the gestation ${ }^{[2]}$ Gross morphometry of the placenta is indicative of the villi branching patterns in the placenta which facilitate the efficient transport of substances to and from the fetus. Placenta morphometry is seen to vary from place to place with different maternal factors, genetics, and environmental factors. ${ }^{[1,3]}$

Mining activities are practiced in more than 100 countries in the world where mining companies and individual miners dig minerals and metals out of the ground, trying to meet the increasing demand in industrial production. ${ }^{[4]}$ There is a lot of gold mining activities in Northwestern Tanzania in Geita, Mara, and Shinyanga regions, and this poses an increased risk of mercury $(\mathrm{Hg})$ and arsenic (As) exposure to the miners as well as the people in the surrounding community. Arsenic is found naturally occurring in the gold ores, and mercury is traditionally used in the purification process. ${ }^{[5,6]}$ A study done in Rwamagasa village, Geita found the concentrations of total $\mathrm{Hg}$ and As ranged 2-920 $\mu \mathrm{g} / \mathrm{l}$ and 43-110 $\mu \mathrm{g} / \mathrm{l}$ respectively in water samples and the soil concentrations for both $\mathrm{Hg}$ and As which were $0.06 \mathrm{mg} / \mathrm{kg}$ and $0.03 \mathrm{mg} / \mathrm{kg}$ respectively. These concentrations are higher than the average levels recommended by the World Health Organisation(WHO) ${ }^{[7]}$ The contaminated soils are used for crop growth and the water is used for drinking for both human and livestock and other domestic activities. ${ }^{[6,7]}$ As a result, people living in the surrounding areas are exposed to heavy metals.

Placenta morphometry has been reported to vary with different maternal factors such as; gestation age, maternal weight, weight gain during pregnancy, pre-pregnancy body mass index, race, maternal illness, and socioeconomic 
status. ${ }^{[8-11]}$ In addition, placenta morphometry has also been reported to be affected by heavy metal exposure. ${ }^{[3,12]}$ The barrier characteristics of the placenta have shown to range with different heavy metals. The placenta is a partial barrier for cadmium, inorganic mercury, and arsenic and is a weaker barrier for lead and organic forms of mercury. ${ }^{[3,13,14]}$ As a result, some of these heavy metals are found concentrated in the placenta tissues and fetal membranes. Increased heavy metal exposure during pregnancy has been associated with changes in placenta function and morphometry. ${ }^{[3,12,15]}$ There is limited information on the perceived effect of heavy metal exposure due to mining activities on placenta morphometry specific to the Tanzanian population. This study aimed to determine the morphometric characteristics of the human placenta and the association between placenta weight and maternal factors in mining and non-mining areas in Northwestern Tanzania.

\section{Subjects and Methods}

This was a comparative cross-sectional study conducted from February 2019 to May 2019. The study was conducted in Geita Regional Referral Hospital and Bugando Medical Center Mwanza representing the mining and non-mining areas respectively. All mothers with singleton pregnancies at term ( $\geq 37$ weeks gestation) and had lived in the respective regions throughout pregnancy were eligible for the study. Following delivery, written informed consent was obtained from each mother for the collection and storage of their placenta for research purposes. Sociodemographic information and pregnancy history were collected using structured questionnaires. Freshly delivered placentas were then collected in labeled containers and transferred to the laboratory. The placentas were first washed under running tap water and then placed on a flat tray for macroscopic examination. Two maximum diameter measurements were taken at right angles and the average considered as the placenta diameter in centimeters. ${ }^{[2,9]}$ The placenta was pierced with a long needle at the center, periphery and at a point between the two. The length of the needle that penetrated through the substance of the placenta was measured in centimeters. ${ }^{[8]}$ The average of these three measurements was taken as the thickness of the placenta in centimeters. The placenta was taken by both hands, and gentle pressure applied on the central part of the fetal surface making the cotyledons on the maternal side of the placenta prominent, placental cotyledons were counted in clockwise direction. ${ }^{2]}$ Umbilical cord length was then recorded in centimeters by adding the fetal stump measurement to the placental stump measurement. ${ }^{[16]}$ Placental weight was then taken in grams using a digital weighing scale (SF-400 with a capacity of $7 \mathrm{~kg} * 1 \mathrm{~g}$, made in China) after trimming of placental membranes and excision of the umbilical cord. ${ }^{[9,17]}$ Data was analyzed using SPSS (Statistical Package for Social Science) version 20.0. Descriptive statistics were used to summarize the demographic characteristics and pregnancy history. A comparative analysis of placenta morphometry between the mining and non-mining area was done using the independent samples t-test. Associations between placenta weight and maternal factors was done using a multi-level linear analysis with respect to study site, and p-value $<0.05$ was considered significant.

Ethical clearance to conduct the study was obtained from Makerere University School of Biomedical Sciences Research and Ethics Committee and the Joint Bugando Medical Center/ Catholic university of Health and Allied Sciences Ethics \& Review Committee. Written informed consent was obtained from all participants prior to enrolment in this study.

\section{Results}

Table 1: Baseline maternal demographics and pregnancy history among singleton births

\begin{tabular}{|l|l|l|}
\hline Demographic variables & $\begin{array}{l}\text { Non-mining area } \\
(\mathbf{n = 2 4 5})\end{array}$ & $\begin{array}{l}\text { Mining area } \\
(\mathbf{n = 2 4 5})\end{array}$ \\
\hline Maternal age, years & $28(24-32)$ & $25(21-30)$ \\
\hline Marital status & & \\
\hline Married & $231(94.3 \%)$ & $235(95.9 \%)$ \\
\hline Education level & & \\
\hline None & $4(1.6 \%)$ & $19(7.8 \%)$ \\
\hline Primary & $75(30.6 \%)$ & $176(71.8 \%)$ \\
\hline Secondary & $90(36.7 \%)$ & $39(15.9 \%)$ \\
\hline Higher education & $76(31.0 \%)$ & $11(4.5 \%)$ \\
\hline Occupation & & \\
\hline Housewife or none & $60(24.5 \%)$ & $8(3.3 \%)$ \\
\hline Student & $7(2.9 \%)$ & $1(0.4 \%)$ \\
\hline Farmer & $15(6.1 \%)$ & $198(80.8 \%)$ \\
\hline Self-employed & $91(37.1 \%)$ & $22(9.0 \%)$ \\
\hline Salaried & $72(29.4 \%)$ & $16(6.5 \%)$ \\
\hline Parity & & \\
\hline Nulliparous & $63(25.7 \%)$ & $62(25.3 \%)$ \\
\hline 1 previous pregnancy & $63(25.7 \%)$ & $53(21.6 \%)$ \\
\hline Multiparous & $83(33.9 \%)$ & $70(28.6 \%)$ \\
\hline Grand multipara & $36(14.7 \%)$ & $60(24.5 \%)$ \\
\hline Mode of delivery & & \\
\hline Spontaneous vaginal delivery & $167(68.4 \%)$ & $218(92.8 \%)$ \\
\hline Gestation age at delivery, weeks & $39(38-40)$ & $39(38-40)$ \\
\hline Data are n (\%) or median (IQR) & &
\end{tabular}

Data are $\mathrm{n}(\%)$ or median (IQR).

Table 2: Placenta morphometry characteristics for each area

\begin{tabular}{|c|c|c|c|c|c|}
\hline Variables & $\begin{array}{l}\text { Non- } \\
\text { mining } \\
\text { area } \\
(\mathrm{n}=\mathbf{2 4 5})\end{array}$ & $\begin{array}{l}\text { Mining } \\
\text { area } \\
(n=245)\end{array}$ & $\begin{array}{l}\text { Mean } \\
\text { difference } \\
(95 \% \mathrm{CI}) *\end{array}$ & df & $\begin{array}{l}\mathbf{t} \\
\text { (P- } \\
\text { value*) }\end{array}$ \\
\hline Weight (g) & $\begin{array}{l}465.9 \\
(101.2)\end{array}$ & $\begin{array}{l}443.6 \\
(82.7)\end{array}$ & $\begin{array}{l}23.3(5.94- \\
38.75)\end{array}$ & 488 & $\begin{array}{l}2.8 \\
(0.008)\end{array}$ \\
\hline $\begin{array}{l}\text { Diameter } \\
(\mathrm{cm})\end{array}$ & $19.0(1.9)$ & $18.3(1.7)$ & $\begin{array}{l}0.7(0.43- \\
1.07)\end{array}$ & 488 & $\begin{array}{l}4.7 \\
(0.000)\end{array}$ \\
\hline $\begin{array}{l}\text { Thickness } \\
\text { (cm) }\end{array}$ & $\begin{array}{l}1.52 \\
(0.32)\end{array}$ & $\begin{array}{l}1.61 \\
(0.38)\end{array}$ & $\begin{array}{l}-0.09(-0.16- \\
-0.03)\end{array}$ & 488 & $\begin{array}{l}-2.9 \\
(0.004)\end{array}$ \\
\hline $\begin{array}{l}\text { Cord length } \\
(\mathrm{cm})\end{array}$ & $\begin{array}{l}49.0 \\
(12.7) \\
\end{array}$ & $\begin{array}{l}50.1 \\
(10.4) \\
\end{array}$ & $\begin{array}{l}-1.1(-3.1- \\
1.0)\end{array}$ & 488 & $-1(0.313)$ \\
\hline $\begin{array}{l}\text { Cotyledon } \\
\text { number }\end{array}$ & $20(4.5)$ & $19(3.7)$ & $\begin{array}{l}1(0.56- \\
2.03)\end{array}$ & 488 & $\begin{array}{l}2.7 \\
(0.001)\end{array}$ \\
\hline
\end{tabular}

Data are mean (SD). *P-values calculated with independent samples t-test

A total of 490 mothers were included in this study with equal representation from each group. The characteristics of the mothers in mining and non-mining areas were moderately similar with two exceptions; most of the mothers $(90 / 245,36.7 \%)$ in the non-mining area had attained secondary level education while the majority of the mothers $(176 / 245,71.8 \%)$ in the mining area had received primary education. Most of the mothers $(91 / 245,37.1 \%)$ in the nonmining area were self-employed while the majority of the mothers $(198 / 245,80.8 \%)$ in the mining area were farmers. The sociodemographic characteristics are summarized in 
[Table 1].

The mean weight of placentas from the non-mining area $(465.9 \pm 101.2 \mathrm{~g})$ was higher than that of the mining area $(443.6 \pm 82.7 \mathrm{~g})$. This weight difference of $23.3 \mathrm{~g}(95 \% \mathrm{CI}$ 5.94 to 38.75 ) was statistically significant $\mathrm{t}(488)=2.8, \mathrm{p}=$ 0.008 . The mean placenta diameter and cotyledon number were also significantly higher in the non-mining area than in the mining area. On the other hand, the mean placenta thickness was significantly lower in the non-mining areas $(\mathrm{p}=0.004)$; and the cord length was similarly lower in the non-mining areas, but the difference was not significant $\mathrm{p}=0.313$ [Table 2].

Using a multilevel linear model with respect to study site, the impact of maternal risk factors on placenta weight was examined. As shown in Table 3, in the univariable model, increase in maternal age and maternal weight on first day of antenatal clinic (maternal weight on booking) were associated with significant increase in placenta weight. In the multivariable model maternal weight on booking was found to be a predictor for placenta weight, such that for a unit increase in maternal weight on booking for any two mothers with the same age, parity, placenta diameter and placenta thickness placenta weight increased by $0.64 \mathrm{~g}$. The intra cluster correlation coefficient for site is 0.2 (95\% CI $0.058-0.321)$.

Table 3: Multilevel linear model of maternal characteristics in placenta weight variations

\begin{tabular}{|l|l|l|l|l|}
\hline Variables & $\begin{array}{l}\text { Univariable model Estimates of } \\
\text { fixed effects (95\% CI) }\end{array}$ & P-value & $\begin{array}{l}\text { Multivariable model Estimates of fixed } \\
\text { effects (95\% CI) }\end{array}$ & P-value \\
\hline Age & $1.65(0.25-3.05)$ & 0.021 & $-0.67(-2.03-0.69)$ & 0.332 \\
\hline Parity & $3.32(-0.89-7.53)$ & 0.122 & $1.23(-2.49-4.94)$ & 0.516 \\
\hline HB & $4.30(-2.68-11.27)$ & 0.226 & $-1.22(-4.97-2.53)$ & 0.524 \\
\hline Maternal weight on booking & $2.46(1.79-3.13)$ & 0.000 & $0.64(0.15-1.13)$ & 0.010 \\
\hline Placenta diameter & $29.57(25.88-33.26)$ & 0.000 & $37.50(34.21-40.80)$ & 0.000 \\
\hline Placenta thickness & $112.44(91.5-133.36)$ & 0.000 & $173.48(155.93-191.03)$ & 0.000 \\
\hline Cord length & $1.75(1.06-2.40)$ & 0.000 & $0.45(-0.035-0.941)$ & 0.069 \\
\hline Placenta weight & 1 & - & 1 & - \\
\hline
\end{tabular}

\section{Discussion}

We set out to determine the morphometric characteristics of the human placenta and association between placenta weight with maternal factors in mining and non-mining areas in Northwestern Tanzania. The mean placenta weight, diameter, and cotyledon numbers were significantly higher in the non-mining area than in the mining area. Furthermore, an increase in maternal weight on booking and maternal age were associated with increase in placenta weight.

The placentas in the mining area were on average lighter, had a smaller diameter and fewer cotyledons compared to the non-mining area. Similarly; Zadrożna et al. reported lighter placentas from contaminated areas due to coal, zinc, and lead mining compared to less contaminated areas. ${ }^{[3]}$ Some studies have also reported lighter placentas with increased concentrations of heavy metals in the placenta mass, cord, and maternal blood. ${ }^{[12,18]}$ The differences in morphometry seen in placentas from the two areas may be explained in part by the mining activities that increase the exposure to heavy metals in the mining area. Heavy metals are thought to cause hyper mature differentiation of villi at the expense of the inter-villous space leading to restriction of maternal blood supply and the physical abilities of diffusion and nutrient transport. ${ }^{[3]}$ This alteration in placenta function may subsequently lead to restricted placenta growth and the observed morphometric parameters. Other factors that could also explain these differences could be differences in maternal nutrition status and genetic variations in the two regions.

The mean placenta thickness, on the other hand, was higher in the mining area than the non-mining area. This finding is contrary to what was reported in a study from Saudi Arabia, where placenta thickness decreased with increased heavy metal exposure. ${ }^{[12]}$ Some studies have shown that the concentration of certain types of heavy metal in the placenta mass or fetal membranes could correlate either negatively or positively with placenta morphometric variables. ${ }^{[19]}$ These

findings suggest that different heavy metals could have different influences on placenta morphometry, and this could further explain the differences seen in the placenta thickness in the two areas. Also; the higher placenta thickness in the mining area in this study might be attributed by overproduction of the villi in the placenta due to heavy metal exposure as a result of mining activities, a phenomena that is coherent with that seen in uteroplacental hypoxia with reduced intraplacental oxygenation. ${ }^{[3]}$

In this study, there was an increase in placental weight per unit increase in maternal weight. Maternal weight gives an overview of the maternal nutritional status. Different studies have also shown an association between maternal weight and placenta weight. ${ }^{[20-22]}$ Proper maternal nutrition facilitates proper growth and development of the placenta and ultimately the developing fetus. ${ }^{[23]}$

In addition, there was a significant increase in placenta weight with maternal age in the univariable model. This finding is similar to that reported by Afodun et al. (2015) and Balihallimath et al. (2015) where they all established that placentas from mothers in the 20-30 year age group had heavier placentas compared to those below 20 years. ${ }^{[24,25]}$ This increase in placenta morphometry result from improved nutrition status, and maturation of the reproductive system as the mother's age progresses from the teen years towards adulthood. ${ }^{[25]}$ This, in turn, favors proper growth and development of the placenta.

Low maternal haemoglobin concentration has been associated with higher placenta weights in different studies, ${ }^{[8,26,27]}$ on the contrary there were no significant associations between maternal haemoglobin levels with placenta weight in the current study. The findings in the current study could be as a result of a relatively small sample size as compared to the previous studies. Low maternal haemoglobin may lead to maternal anemia, thus 
causing hypoxemia which stimulates growth to increase the surface area for diffusion of oxygen as a compensatory mechanism. ${ }^{[8]}$

In the present study there was no significant association between parity and placenta weight; Balihallimath et al. reported similar findings. ${ }^{[25]}$ On the contrary Roland et al. reported a significant increase in placenta weight with parity. ${ }^{[28]}$ One of the theories put forward to explain why placenta weight would increase with parity was due to maternal sensitization to paternal antigens found on the fetus leading to both placental and fetal growth, it was also observed that the greatest increments occur between parity one and two with little or no increment occurring with higher parity. ${ }^{[29]}$ A study by Afodun et al. reported a similar observation where there was an increase in placenta weight between parity one and two and a decrease in mean placenta weight from the parity of 3 and above. ${ }^{[24]}$

The present study was conducted in Northwestern Tanzania with specific interest to the mining area and non-mining area. Therefore, generalizability of findings to the Tanzanian general population may be limited. Furthermore, the current study did not measure heavy metal concentrations in the placenta mass to estimate the exact relation between heavy metal concentrations and variation in placenta morphometry. More so; the difference in socioeconomic setting between the study sites (non-mining area being in an urban setting compared to mining area in a rural setting) could be a potential source of bias.

\section{Conclusion}

There were significant differences in the mean placenta morphometric variables between the mining and non-mining areas. These findings suggest that increased risk to heavy metal exposure among other factors affects placenta morphometry. Maternal weight on booking significantly predicted placenta weight in the current study. Further research can be done to determine heavy metal concentrations in the placenta mass, cord and maternal blood and their effect on placenta morphology and morphometry in the Tanzanian population.

\section{Acknowledgments}

We would like to thank the hospital managements of Geita Regional Referal hospital and Bugando Medical Center who gave permission to conduct the study in their hospitals. Our sincere appreciaton goes to mothers for their willingness to participate in the study. We would also like to thank the study nurses for their help in participant recruition and administering surveys.

\section{Funding}

The study was funded by a training grant from the Catholic University of Health and Allied Sciences.

\section{References}

1. Rupa, Shirol VS, Anita MG, Tyagi N. Clinical determinants of placental morphometry and birth. 2013.

2. Kulandaivelu A. Morphology and Morphometric Study of Human Placenta in Rural Southern India. $\mathrm{Br} \mathrm{J}$ Med Med Res
2014;4(15):2995-3008.

3. Zadrożna M, Nowak B, Żołnierek M, Zamorska L, Niweliński J. Human Placenta as a Biomarker of Environmental Toxins Exposure - Long-Term Morphochemical Monitoring. Recent Adv Res Hum Placenta [Internet] 2012 [cited 2019 Dec 28];Available from: https://www.intechopen.com/books/recent-advances-inresearch-on-the-human-placenta/human-placenta-as-a-biomarkerfor-monitoring-maternal-and-fetal-environment

4. Weber-Fahr M. Treasure or trouble? Mining in developing countries. World Bank Int Finance Corp Wash DC 2002;

5. Charles E, Thomas DS, Dewey D, Davey M, Ngallaba SE, Konje E. A cross-sectional survey on knowledge and perceptions of health risks associated with arsenic and mercury contamination from artisanal gold mining in Tanzania. BMC Public Health 2013;13:74.

6. van Straaten P. Human exposure to mercury due to small scale gold mining in northern Tanzania. Sci Total Environ 2000;259(1-3):4553.

7. Nyanza EC, Dewey D, Thomas DSK, Davey M, Ngallaba SE. Spatial Distribution of Mercury and Arsenic Levels in Water, Soil and Cassava Plants in a Community with Long History of Gold Mining in Tanzania. Bull Environ Contam Toxicol 2014;93(6):716-21.

8. Baptiste-Roberts K, Salafia CM, Nicholson WK, Duggan A, Wang N-Y, Brancati FL. Maternal risk factors for abnormal placental growth: The national collaborative perinatal project. BMC Pregnancy Childbirth 2008;8(1):44.

9. Keche HA, Keche AS. Morphometric differentiation between placenta in PIH and normal pregnancy. Int J Med Sci Public Health $2015 ; 4: 250-5$.

10. McNamara H, Hutcheon JA, Platt RW, Benjamin A, Kramer MS, Risk Factors for High and Low Placental Weight: Risk factors for high and low placental weight. Paediatr Perinat Epidemiol 2014;28(2):97-105.

11. Raghunath G, Vijayalakshmi SV. A study on the morphology and the morphometry of the human placenta and its clinical relevance in a population in Tamilnadu. J Clin Diagn Res 2011;5(2):282-286.

12. Al-Saleh I, Al-Rouqi R, Obsum CA, Shinwari N, Mashhour A, Billedo $\mathrm{G}$, et al. Interaction between cadmium $(\mathrm{Cd})$, selenium $(\mathrm{Se})$ and oxidative stress biomarkers in healthy mothers and its impact on birth anthropometric measures. Int J Hyg Environ Health 2015;218(1):66-90.

13. Agrawal A. Toxicity and Fate of Heavy Metals with Particular Reference to Developing Foetus. Adv Life Sci 2012;2(2):29-38.

14. Gundacker $C$, Hengstschläger $M$. The role of the placenta in fetal exposure to heavy metals. Wien Med Wochenschr 2012;162(910):201-6.

15. Caserta D, Graziano A, Lo Monte G, Bordi G, Moscarini M. Heavy metals and placental fetal-maternal barrier: a mini-review on the major concerns. Eur Rev Med Pharmacol Sci 2013;17(16):2198_ 206.

16. Georgiadis L, Keski-Nisula L, Harju M, Räisänen S, Georgiadis S, Hannila M-L, et al. Umbilical cord length in singleton gestations: A Finnish population-based retrospective register study. Placenta 2014;35(4):275-80.

17. Burton GJ, Sebire NJ, Myatt L, Tannetta D, Wang Y-L, Sadovsky $\mathrm{Y}$, et al. Optimising sample collection for placental research. Placenta 2014;35(1):9-22.

18. Punshon T, Li Z, Jackson BP, Parks WT, Romano M, Conway D, et al. Placental metal concentrations in relation to placental growth, efficiency and birth weight. Environ Int 2019;126:533-42.

19. Kot K, Kosik-Bogacka D, Łanocha-Arendarczyk N, Malinowski W, Szymański S, Mularczyk M, et al. Interactions between 14 Elements in the Human Placenta, Fetal Membrane and Umbilical Cord. Int J Environ Res Public Health 2019;16(9):1615.

20. Hibbert JM, Davidson S, Hall JS, Jackson AA. Maternal prepregnancy weight and placental weight determine birth weight in normal Jamaican infants. West Indian Med J 1999;48(4):216-20.

21. Nwogu C, Adetuyi I, Okunade K, Osanyin G, Oluwole A. Placental weight and perinatal outcome among parturients at a university teaching hospital in Lagos, Nigeria. Trop J Obstet Gynaecol 2018;35(3):322.

22. Soliman AT, Eldabbagh M, Saleem W, Zahredin K, Shatla E, Adel 
A. Placental weight: Relation to maternal weight and growth parameters of full-term babies at birth and during childhood. J Trop Pediatr 2013;59(5):358-64.

23. Gernand AD, Christian P, Paul RR, Shaikh S, Labrique AB, Schulze KJ, et al. Maternal Weight and Body Composition during Pregnancy Are Associated with Placental and Birth Weight in Rural Bangladesh. J Nutr 2012;142(11):2010-6.

24. Afodun AM, Ajao MS, Enaibe BU. Placental Anthropometric Features: Maternal and Neonate Characteristics in North Central Nigeria [Internet]. Adv. Anat. 2015;13:19-23.

25. Balihallimath RL, Shirol VS, Tyagi NK, Gan AM, Desai SP. Maternal determinants of placental morphometry and birth weight. Int J Med Sci Public Health 2015;4(4):508-516.

26. Beischer NA, Sivasamboo R, Vohra S, Silpisornkosal S, Reid S. Placental Hypertrophy In Severe Pregnancy Anaemia. BJOG Int J
Obstet Gynaecol 1970;77(5):398-409.

27. Larsen S, Bjelland EK, Haavaldsen C, Eskild A. Placental weight in pregnancies with high or low hemoglobin concentrations. Eur J Obstet Gynecol Reprod Biol 2016;206:48-52.

28. Roland MCP, Friis CM, Godang K, Bollerslev J, Haugen G, Henriksen T. Maternal Factors Associated with Fetal Growth and Birthweight Are Independent Determinants of Placental Weight and Exhibit Differential Effects by Fetal Sex. PLoS ONE 2014;9(2):e87303.

29. Warburton D, Naylor AF. The effect of parity on placental weight and birth weight: an immunological phenomenon? A report of the Collaborative Study of Cerebral Palsy. Am J Hum Genet 1971;23(1):41-54.

Copyright: (C) the author(s), 2020. It is an open-access article distributed under the terms of the Creative Commons Attribution License (CC BY 4.0), which permits authors to retain ownership of the copyright for their content, and allow anyone to download, reuse, reprint, modify, distribute and/or copy the content as long as the original authors and source are cited.

How to cite this article: Ndibalema M, Mwaka E, Rambau P, Munabi I, Buwembo W. Morphometry of the Human Placenta in Mining and Non-Mining Areas in Northwestern Tanzania; A Comparative Cross-Sectional Study. Acad. Anat. Int. 2020;6(1):49-53.

DOI: dx.doi.org/10.21276/aanat.2020.6.1.11

Source of Support: Nil, Conflict of Interest: None declared. 